\title{
Optimizing Final Electrode Placement Based on Intraoperative Neurophysiological Evaluation during Subthalamic Deep Brain Stimulation for Parkinson's Disease
}

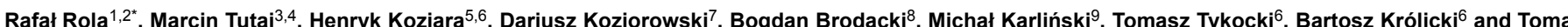
Mandat ${ }^{5,6}$

${ }^{1}$ Department of Neurology, Military Institute of Aviation Medicine, Warsaw, Poland

${ }^{2}$ First Department of Neurology, Institute of Psychiatry and Neurology, Warsaw, Poland

${ }^{3}$ Department of Neurology, Jagiellonian University, Cracow, Poland

${ }^{4}$ Medtronic, Poland

${ }^{5}$ Department of Nervous System Neoplasms, Centre of Oncology, M aria Skłodowska -Curie Institute, Warsaw, Poland

${ }^{6}$ Department of Neurosurgery, Institute of Psychiatry and Neurology, Warsaw, Poland

${ }^{7}$ Department of Neurology, Warsaw Medical University, Warsaw, Poland

${ }^{8}$ Department of Neurology, Military Institute of Medicine, Warsaw, Poland

${ }^{9}$ Second Department of Neurology, Institute of Psychiatry and Neurology, Warsaw, Poland

*Corresponding author: Rafal Rola, Military Institute of Aviation Medicine, Poland, Tel: +48 2261852922; E-mail: rafal.rola@wp.pl

Received date: May 04, 2016; Accepted date: July 11, 2016; Published date: July 18, 2016

Copyright: ( 2016 Rola R, et al. This is an open-access article distributed under the terms of the Creative Commons Attribution License, which permits unrestricted use, distribution, and reproduction in any medium, provided the original author and source are credited.

\begin{abstract}
Background and purpose: Target point identification based solely on MRI and CT of subthalamic nucleus (STN) in deep brain stimulation procedures (DBS) for Parkinson's disease (PD) might have suboptimal clinical effects. The authors analyse alterations of permanent electrode location depending on neurophysiological evaluation compared to an anatomically based calculated target.

Materials and methods: The group comprised 66 patients (32 females and 34 males) aged 57.6 (38-76) years, in whom 131 electrodes were implanted. The patients were qualified for the surgery according to the CAPSIT-PD criteria. STN was identified using the direct and indirect methods, based on $1.5 \mathrm{~T}$ MRI and CT. The surgery was performed under local anesthesia. Two to 5 microelectrodes were used for microrecording and macrostimulation.
\end{abstract}

Results: Anterior $(49.2 \%)$, central $(35.6 \%)$ and lateral $(13.6 \%)$ trajectories were most frequently used for permanent electrode placement. The electrode was most frequently placed at a depth of $+2 /+3(58.3 \%)$ or +1 and $+5 \mathrm{~mm}(36.4 \%)$ with regard to the planned target point. Differences in selecting the trajectory and depth of the final electrode position were statistically significant $(p<0.05)$.

Conclusion: DBS implantation based only on anatomical identification of STN can lead to suboptimal results. Additional application of intrasurgical neurophysiological analysis may increase the effectiveness of the STN DBS therapy for PD.

Keywords: Microrecording; Macrostimulation; Parkinson's disease; Deep brain stimulation; Subthalamic nucleus

\section{Introduction}

Parkinson's disease (PD) is a cause of disability in $1.5 \%$ of the population aged over 60 years of age and is an important socioeconomic problem. So far, no specific treatment for this neurodegenerative process is available. Symptomatic treatment of PD consists mainly of pharmacological supplementation and modulation of the dopaminergic system.

In $4-10 \%$ of patients with $\mathrm{PD}$, insufficient pharmacological treatment may force a neurosurgical treatment trial. Neurosurgical ablative treatment (pallidotomy, thalamotomy) of PD was introduced in the 1940s and was effective in selected patients. However, the risk of irreversible neurological deficits after the surgery was the main cause of progress of functional neurosurgery at the time of the introduction of L-dopa for the treatment of PD.

A breakthrough in the neurosurgical treatment of movement disorders was the introduction of modern systems for deep brain stimulation (DBS) in the 1980s. DBS has similar efficacy to that observed after ablative surgery, with far less risk of permanent complications. A milestone for the understanding and treatment of PD was the development in 1976 of a laboratory model of dopaminergic system disorders and identification of the optimal surgery target for the treatment of major PD symptoms in the subthalamic nucleus (STN). Due to the occurrence of serious side-effects after surgical ablation of the subthalamic nucleus (hemibalismus), only a few centres had used this target before the introduction of DBS surgery [1-5]. 
Citation: Rola R, Tutaj M, Koziara H, Koziorowski D, Brodacki B, et al. (2016) Optimizing Final Electrode Placement Based on Intraoperative Neurophysiological Evaluation during Subthalamic Deep Brain Stimulation for Parkinson's Disease. J Neurol Neurophysiol 7: 384 . doi: $10.4172 / 2155-9562.1000384$

Page 2 of 6

The introduction of modern techniques of neuroimaging, including MRI, allowed very precise identification of brain structures, including the STN [6-18], in a minimally invasive manner. However, the anatomic identification of STN by MRI may not correspond to its neurophysiological activity, thus hindering achievement of the optimum therapeutic effect [19-26].

\section{Patients}

The study group comprised 66 consecutive patients (32 women and 34 men) who underwent implantation of a 131 STN DBS system because of PD. Microrecordings were conducted with 462 trajectories.

Age at surgery was on average $57.6(38-76)$ years and disease duration was on average $10(6-21)$ years. Patients were qualified for surgery based on the criteria contained in CAPSIT-PD [27-30]. The qualification process was performed in reference centers involved in the treatment of neurological diseases. The patients who qualified for the surgery were in stages II-IV disease according to the Hoehn-Yahr scale, with a mean daily demand for L-dopa of $1100 \mathrm{mg}$ (95\% CI: 9381262). The mean UPDRS III was 49.2 (95\% CI: 45.5-52.8) in the OFF and $20.9(18.3-23.8)$ in the ON phase (Table 1).

\begin{tabular}{|l|l|l|}
\hline & Mean $(95 \% \mathrm{Cl})$ & Median (Range) \\
\hline Age [yrs] & $57.6(55,7-59,5)$ & $58(38-76)$ \\
\hline UPDRS III before DBS & & \\
\hline - OFF phase & $49.2(45,6-52,8)$ & $48(15-77)$ \\
\hline - ON phase & $20.9(18,3-23,8)$ & $19(7-53)$ \\
\hline - (OFF-ON)/OFF ratio (\%) & $52.0 \%(47,7-56,4)$ & $54.4 \%(21,3-8,4)$ \\
\hline Active DBS treatment & & \\
\hline - ON phase & $9.8(7,9-12,2)$ & $8(2-47)$ \\
\hline Improvement after DBS $\dagger$ & $46.3 \%(40,4-52,1)$ & $49.2 \%(9,1-90,0)$ \\
\hline
\end{tabular}

Table 1: Demographic data ( $†$ Calculated according to the equation (III UPDRS score in ON phase before DBS treatment minus III UPDRS score in ON phase with DBS)/III UPDRS score in ON phase before DBS treatment).

\section{Surgery and neurophysiological studies}

All patients underwent 1.5 T MRI. Scans were performed using the following protocol: T2 axial $1.5 \mathrm{~mm} /$ slice gap 0.2 , T1 contrast axial + $1.5 \mathrm{~mm} /$ slice gap 0.2. Pharmacological treatment was discontinued at least $12 \mathrm{~h}$ before surgery. Patients did not receive anticoagulation for at least 7 days before surgery except for low molecular weight heparin. Procedures were carried out under local and general anesthesia. After a CT with stereotactic frame acquisition (with contrast, every $1.5 \mathrm{~mm}$, no gantry tilt), MRI image fusion was performed (Framelink 5.3, Medtronic).

The patient was then moved to the operating theatre. The indirect method was used to identify the target point (mid. AC-PC: $11,-2,-4$ ) and directly by modifying the target depending on the MRI image [7-18]. After determining the entry point using a stereotactic frame (Leksell, Elekta), the burr hole was made around the coronal suture (3$5 \mathrm{~cm}$ lateral to the midline) and a skull-fastening system was attached to the micro- and macroelectrode positioning systems. During macrostimulation the following clinical symptoms were assessed: rigidity, bradykinesia, resting tremor and side-effects [31-34]. The macrostimulation was supervised and conducted by a neurophysiologist and neurologist or neurosurgeon trained in the evaluation of extrapyramidal diseases. The microrecording and macrostimulation have been archived.

Microelectrode recordings (MERs) of STN neuronal activity and adjacent structures were carried out using a biological signal amplifier and software devoted to recording and analysing extracellular potentials generated by single neurons (Leadpoint, Medtronic). Extracellular recordings of spontaneous activity of neurons, the target structure and neighbouring structures (thalamus, zona incerta, substantia nigra), were performed for 2 to 5 trajectories (central, anterior, medial, lateral and posterior). Before each recording, electrode resistance was measured (minimum electrode resistance was $>1 \mathrm{k} \Omega$ ) and potential sources of artifacts eliminated. Electrophysiological activity was recorded from $-10 \mathrm{~mm}$ to $+6 \mathrm{~mm}$ from the target point. The bandwidth for recording was $3 \mathrm{~Hz}$ to 10 $\mathrm{kHz}$. Spontaneous activity of neurons was recorded at intervals of 1 $\mathrm{mm}$. The recording time was at least $30 \mathrm{~s}, 15 \mathrm{~s}$ after the end of micromanipulator motion of the electrodes. The spontaneous activity of the neurons was analysed visually and the average frequency of APs of neurons located at the microelectrode was also analysed. STN neurons were identified based on the following criteria: a two-fold increase in the amplitude of background activity and irregular discharges of action potentials in the frequency range of 30-60 Hz. The reticular part of the substantia nigra $(\mathrm{SNr})$ was identified as regular discharges of APs with a frequency of 70-90 Hz, and the amplitude of the background potentials were lower than in the STN. Each trajectory was assessed based on the microrecording examination limits on the STN. The trajectory that registered the best STN activity was chosen for electrical stimulation to assess the effectiveness of the DBS. In the case of unsatisfactory clinical efficacy or adverse reactions to lowintensity stimulus $(<3 \mathrm{~mA})$, stimulation of STN was situated at points within the next trajectory. Macrostimulation was performed using a rectangular current stimulus with a duration of $60 \mu$ supplied with a frequency of $130 \mathrm{~Hz}$ in the current range, from 0 to $8 \mathrm{~mA}$.

The current amplitude was increased by $1 \mathrm{~mA}$ to evaluate the clinical effect of stimulation. If any side-effects occurred, the stimulation current was not increased. If adverse reactions were observed at low stimulus intensity $(<3 \mathrm{~mA})$, stimulation was initiated in the next trajectory. The effect of stimulation was evaluated clinically with the influence of the following symptoms: rigidity, bradykinesia and tremor. The final locations for permanent implantation of electrodes were selected based on the effectiveness of the stimulation and the lack of side-effects. After identifying the optimal target for stimulation, the stimulating electrode (Medtronic, 3389) was removed and a permanent brain electrode was introduced under the control of a fluoroscope. The electrode was attached to the bone using a latch (Stimlock, Medtronic). After the closure of the wound, the stereotactic frame was removed. After receiving antiparkinsonian medication the patient was subjected to general anesthesia. After the liaison of wire under the skin, the stimulator was introduced into the subcutaneous tissue around the subclavian or abdominal wall. Control imaging studies (CT) were performed within $24 \mathrm{~h}$ of surgery. The pacemaker programming process took place 6 weeks after surgery. In two patients the electrodes were implanted unilaterally; in the remaining cases, bilaterally. In one patient, the stimulating system was removed and reimplanted due to local infection. 
Citation: $\quad$ Rola R, Tutaj M, Koziara H, Koziorowski D, Brodacki B, et al. (2016) Optimizing Final Electrode Placement Based on Intraoperative Neurophysiological Evaluation during Subthalamic Deep Brain Stimulation for Parkinson's Disease. J Neurol Neurophysiol 7: 384 . doi: $10.4172 / 2155-9562.1000384$

Page 3 of 6

\section{Statistical Analysis}

Variables measured on a nominal or ordinal scale are presented in percentages with a $95 \%$ confidence interval (95\% CI). Normal qualitative variables are presented both by the arithmetic mean of $95 \%$ and the median with the range of values in cases of the non-Gaussian distributions. The comparative analysis of qualitative variables routinely used the chi-square test and, if the expected frequencies $<5$ exact two-sided, Fisher's exact test. Quantitative variables at subsequent time points were compared using the Wilcoxon test sequence pairs. A level of $\mathrm{p}<0.05$ was adopted for all tests of statistical significance. Statistical calculations were performed using STATISTICA 8.0 PL (StatSoft, 2008).

\section{Results}

In the initial period, cathodal stimulation on contacts $(C+, 0-, 1-)$ was applied with a frequency of $130 \mathrm{~Hz}$, with a pulse width of $60 \mu \mathrm{s}$ and an amplitude of up to $1.0 \mathrm{~V}$ [35]. Then, depending on the response, the parameters of stimulation were modified by introducing bipolar stimulation and increasing the amplitude to $2.5 \mathrm{~V}$. Controlled clinical evaluations were carried out after 6 months in $50(75.6 \%)$ patients. Reductions in severity of the neurological syndrome quantified by the UPDRS III were evaluated on average at $46.3 \%$ (9.1$90 \%, \mathrm{p}<0.001)$. The mean daily dose of L-dopa was $525 \mathrm{mg}$ (95\% CI: $347-704)$, which was a significant reduction of $48 \%$ as compared to the state before DBS.

Among 66 patients treated with permanent 131 electrodes, the most frequent final positioning trajectories, based on neurophysiological assessment, were as follows: Anterior trajectories (49.2\%), central (35.6\%) and lateral (13.6\%).

The medial and posterior trajectories were chosen in individual cases (Table 2). Differences in the incidence of choice of trajectories were statistically significant $(p<0.05)$ (Figure 1$)$. The depths at which electrodes were left permanently were in all cases different from what had been planned preoperatively. The electrode was in most cases left at a depth of 2 or $3 \mathrm{~mm}$ (58.3\%), followed by 1 or $5 \mathrm{~mm} \mathrm{(36.4 \% )} \mathrm{and} 5$ or $6 \mathrm{~mm}$ (5.3\%) (Figure 2 and Table 2). Differences in frequency between successive groups of depth were statistically significant $(\mathrm{p}<0.05)$ (Figure 2).

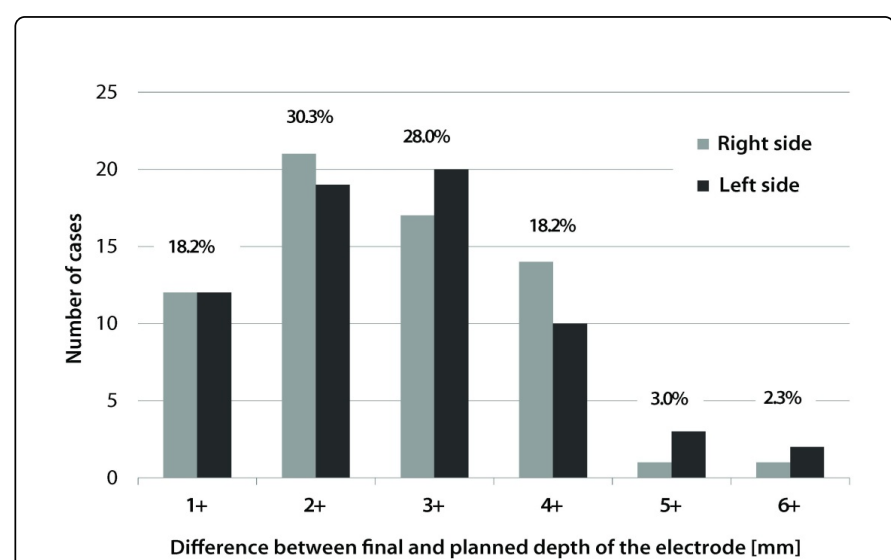

Figure 1: Final placement of the stimulating electrode in respect to planned in MRI target.

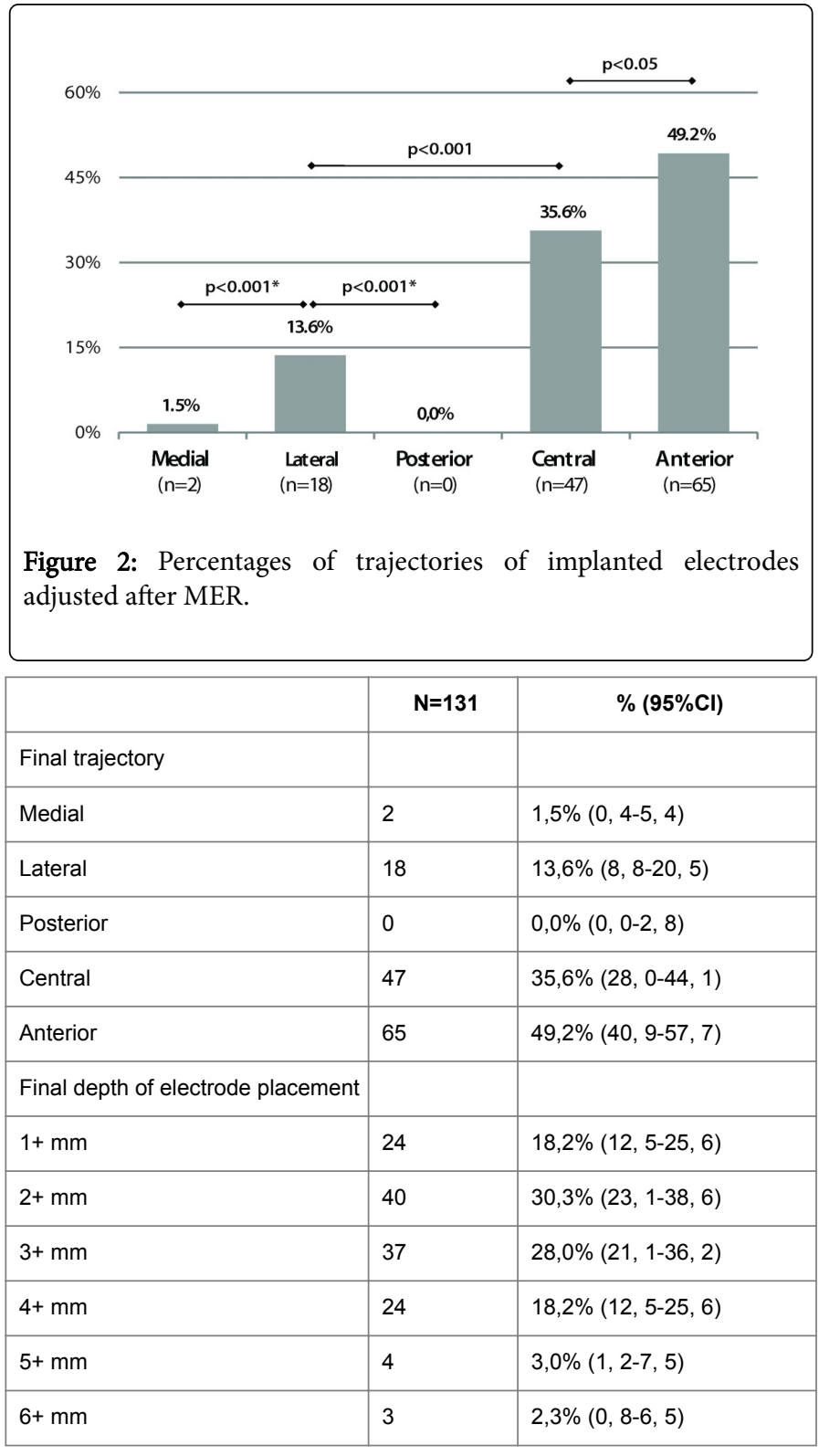

Table 2: Final trajectories and final electrode placement in respect to planned in MRI target.

There was one infectious complication (1/131 implantation-0.76\%), which caused the removal of the system. After three months and the end of antibiotic therapy, the system was effectively reimplanted. Four patients (4/131 implantation-3\%) had erosion of the skin over the pacemaker or connector. No intracranial bleeding was reported at the control CT scan in the presented group of 66 patients with implanted 131 DBS systems in which 462 MER trajectories were performed.

\section{Discussion}

In the 1940s, most authors were already using intraoperative stimulation of the deep brain structures as a test for 'reverse lesions' to identify certain structures (i.e., globus pallidus) during ablative treatments. Intraoperative neurophysiological tests could predict the therapeutic effect of ablative surgery. After turning on the stimulation, 
Citation: Rola R, Tutaj M, Koziara H, Koziorowski D, Brodacki B, et al. (2016) Optimizing Final Electrode Placement Based on Intraoperative Neurophysiological Evaluation during Subthalamic Deep Brain Stimulation for Parkinson's Disease. J Neurol Neurophysiol 7: 384 . doi: $10.4172 / 2155-9562.1000384$

Page 4 of 6

there was improvement in PD symptoms; once it was turned off, symptoms recurred. Maintaining the intraoperative and perioperative stimulation of selected cases improved the effectiveness and safety of ablative procedures. The next natural step was the introduction of permanent pacemakers for DBS [1-3].

In the last two decades functional neurosurgery has developed rapidly, mainly due to the introduction of DBS. In different DBS therapy centers, intraoperative neurophysiological evaluation and/or neuroimaging planning is used to identify the target. Neuroimaging methods of STN identification frequently use a high-pole MRI. Direct target identification is based on high-resolution T2 scans. Indirect identification is based on the location of the anterior and posterior commissure, the nucleus rubber, mammillary bodies and the third ventricle wall. According to some authors, an MRI is sufficient to identify an STN, especially if it is carried out on a high-pole MRI. However, most authors confirm the position of an STN intraoperatively with neurophysiological studies, including the use of microrecording, macrostimulation or both $[8,9,13,14,17,19]$.

\section{The role of neurophysiological evaluation}

MER of neuronal activity has been proven effective in determining the boundaries of a subthalamic nucleus. Analysis of the STN neuronal activity is an important complement to the stereotactic planning of the implantation target for a DBS electrode. MER allows for the evaluation of the real-time activity of STN neurons. This allows the optimal target for permanent electrode placement to be determined neurophysiologically on the basis of trial macrostimulation along the trajectories initially determined by MER [19,21,24,31-34].

In the present study it was found that the most effective clinically permanent electrode trajectories were the anterior, central or lateral trajectories. Stimulation along these trajectories was associated with the largest reduction of Parkinsonian symptoms (with low currents used and no side-effects) evaluated intraoperatively. These observations were further confirmed after the implantation of a DBS system. In long-term follow-up, the improvement in clinical status of patients and the reduction of dopaminergic drugs dosage was about $50 \%$, which is similar to previous reports [36-41].

The mechanism of neurostimulator action is not fully understood. The essential idea of deep brain stimulation action is based on inhibiting structures that are excessively active in the pathological pathways of basal ganglia. The main mechanisms of DBS action are the depolarisation blockade of neurons (the inactivation of sodium ion channels), synaptic depolarisation inactivation, antidromal release of GABA within the basal ganglia network, and activation of local inhibitory mechanisms within the DBS target [6]. The most significant feature of DBS treatment is the possibility of reversible and complete inhibition of hyperactive structures. It is therefore logical and reasonable to implant DBS electrodes in the parts of the target structures that are the most hyperactive-the activity of which is to be modulated. Because the neuroimaging determination of the target point was similar in all patients, the profile of the trajectory chosen as the permanent location of the electrodes (based on neurophysiological evaluation) indicates that the most effective treatment seems to be the stimulation of the anterolateral-area STN. These results are consistent with the previously described clinical and anatomical data, according to the previously described most optimal neurostimulation region, which is the anterior dorso-lateral part of the STN (anterior dorsallateral Forel axis of the forebrain) $[36,37]$.
However, this area, although anatomically defined, is not functionally uniform, and the optimal region for stimulation effects can be in the front (the anterior trajectory) or side (the lateral trajectory) of the STN. Determining the most effective and safe location for DBS therapy is only possible using MERs and test stimulations, which are the only tests that can determine the effects of stimulation of certain parts of the STN in real time and in awake patients. Determining the target based solely on morphological data, even with a high-pole MRI, may not be compatible with a functionally determined target for DBS [21-24,31-34]. Despite the fact that neurophysiological research requires the cooperation of additional staff and is time-consuming, these facts seem to confirm the efficacy of the protocol.

The integrative approach in planning the final target for a DBS electrode (morphological-neuronavigation, neurophysiologicalmicrorecording and functional-MER and intraoperative macrostimulation) allows for the determination of the optimal target for permanent implantation of electrodes. As shown by these results, the final place of implantation of DBS electrodes in most cases was on a different level-2 to $3 \mathrm{~mm}$ from the planned target, and only $35 \%$ of the central trajectory. Optimising the position of the permanent electrode is important for the following reasons: the choice of a target in which the smallest stimulus intensity causes significant clinical effect greatly extends the life of DBS electrodes. The target associated with the lowest rate of side-effects significantly improves the quality of permanent pacing.

DBS implantation is subject to a small risk of bleeding complications, similar to that observed for other stereotactic surgery, and ranges from 0.6 to $3.3 \%$; the incidence of intracranial bleeding producing clinical symptoms remained at $>1 \%$ [32,42-50]. Most authors recognise the use of several microelectrodes to be safe; there was no correlation between the risk of bleeding and the number of microelectrodes used $[32,42,44-48]$. In a retrospective analysis, Mikos et al. described the incidence of bleeding complications up to $4.3 \%-$ however, with the use of transventricular electrodes [43]. Hariz and Fodstad drew attention to the increased risk of bleeding complications when using a larger number of trajectories in their review paper [49], but this review was also based on abstract communications and chapters that were not subject to assessment by reviewers in the process of publication [49]. The analysis, covering up to 644 patients undergoing ablation or DBS, showed no correlation between the number of trajectories and the risk of bleeding during DBS surgery $[44,47]$

\section{Conclusion}

Our results indicate that target identification based on morphological data in most cases is not identical with neurophysiologically assessed targets for deep brain stimulation. There is a risk of suboptimal effects during the implantation of a DBS system based only on neuroimaging. Therefore, intraoperative neurophysiological evaluation seems to be fully justified and should be an integral part of the procedure, despite the increased length of surgery and the need to engage additional staff (a neuroscientist and a neurologist).

\section{References}

1. Pollak P, Fraix V, Krack P, Moro E, Mendes A, et al. (2002) Treatment results: Parkinson's disease. Mov Disord 17: S75-S83. 
Citation: Rola R, Tutaj M, Koziara H, Koziorowski D, Brodacki B, et al. (2016) Optimizing Final Electrode Placement Based on Intraoperative Neurophysiological Evaluation during Subthalamic Deep Brain Stimulation for Parkinson's Disease. J Neurol Neurophysiol 7: 384 . doi: $10.4172 / 2155-9562.1000384$

Page 5 of 6

2. Lang AE (2000) Surgery for Parkinson disease: A critical evaluation of state of the art. Arch Neurol 57: 1118-1125.

3. Lang AE, Widner H (2002) Deep brain stimulation for Parkinson's disease: Patient selection and evaluation. Mov Disord 17: S94-S101.

4. Starr PA, Vitek JL, Bakay RA (1998) Deep brain stimulation for movement disorders. Neurosurg Clin N Am 9: 381-402.

5. Haberler C, Alesch F, Mazal PR, Pilz P, Jellinger K, et al. (2000) No tissue damage by chronic deep brain stimulation in Parkinson's disease. Ann Neurol 48: 372-376.

6. Dostrovsky JO, Lozano A (2002) Mechanism of deep brain stimulation. Mov Disord 17: S63-S68.

7. Acar F, Miller JP, Berk MC, Anderson G, Burchiel KJ (2007) Safety of anterior commissure-posterior commissure-based target calculation of the subthalamic nucleus in functional stereotactic procedures. Stereotact Funct Neurosurg 85: 287-91.

8. Andrade-Souza YM, Schwalb JM, Hamani C, Eltahawy H, Hoque T, et al. (2005) Comparison of three methods of targeting the subthalamic nucleus for chronic stimulation in Parkinson's disease. Neurosurgery 56: 360-368.

9. Bejiani BP, Dormont D, Pidoux B, Yelnik J, Damier P, et al. (2000) Bilateral subthalamic stimulation for Parkinson's disease by using threedimensional stereotactic magnetic resonance imaging and electrophysiological guidance. J Neurosurg 92: 615-625.

10. Benabid AL, Koudsie A, Benazzouz A, Le Bas JF, Pollak P (2002) Imaging of subthalamic nucleus and ventralis intermedius of the thalamus. Mov Disord 17: S123-S129.

11. Breit S, LeBas JF, Koudsie A, Schulz J, Benazzouz A, et al. (2006) Pretargeting for the implantation of stimulation electrodes into the subthalamic nucleus: A comparative study of magnetic resonance imaging and ventriculography. Neurosurgery 58: 83-95.

12. Cuny E, Guehl D, Burbaud P, Gross C, Dousset V, et al. (2002) Lack of agreement between direct magnetic resonance imaging and statistical determination of a subthalamic target. J Neurosurg 97: 591-597.

13. Hariz MI, Krack P, Melvill R, Jorgensen JV, Hamel W, et al. (2003) A quick and universal method for stereotactic visualization of the subthalamic nucleus before and after implantation of deep brain stimulation electrodes. Stereotact Funct Neurosurg 80: 96-101.

14. Kitajima M, Korogi Y, Kakeda S, Moriya J, Ohnari N, et al. (208) Human subthalamic nucleus: Evaluation with highresolution MR imaging at 3.0 T. Neuroradiology 50: 675-81.

15. O'Gorman RL, Shmueli K, Ashkan K, Samuel M, Lythgoe DJ, et al. (2011) Optimal MRI methods for direct stereotactic targeting of the subthalamic nucleus and globus pallidus. Eur Radiol 21: 130-136.

16. Pollo C, Meuli R, Maeder P, Vingerhoets F, Ghika J, et al. (2003) Subthalamic nucleus deep brain stimulation for Parkinson's disease: Magnetic resonance imaging targeting using visible anatomical landmarks. Stereotact Funct Neurosurg 80: 76-81.

17. Richter EO, Hoque T, Halliday W, Lozano AM, Saint-Cyr JA (2004) Determining the position and size of the subthalamic nucleus based on magnetic resonance imaging results in patients with advanced Parkinson disease. J Neurosurg 100: 541-546.

18. Starr PA, Vitek JL, DeLong M, Bakay RA (1999) Magnetic resonance imaging-based stereotactic localization of the globus pallidus and subthalamic nucleus based stereotactic localization of the globus pallidus and subthalamic nucleus. Neurosurgery 44: 303-313.

19. Zonenshayn M, Rezai AR, Mogilner AY, Beric A, Sterio D, et al. (2000) Comparison of anatomic and neurophysiological methods for subthalamic nucleus targeting. Neurosurgery 47: 282-294.

20. Coste J, Ouchchane L, Sarry L, Derost P, Durif F, et al. (2009) New electrophysiological mapping combined with MRI in parkinsonian's subthalamic region. Eur J Neurosci 29: 1627-1633.

21. Godinho F, Thobois S, Magnin M, Guenot M, Polo G, et al. (2006) Subthalamic nucleus stimulation in Parkinson's disease: Anatomical and electrophysiological localization of active contacts. J Neurol 253: 1347-55.
22. Hamani C, Richter EO, Andrade-Souza Y, Hutchison W, Saint-Cyr JA, et al. (2005) Correspondence of microelectrode mapping with magnetic resonance imaging for subthalamic nucleus procedures. Surg Neurol 63: 249-53.

23. Lehmann RM (2001) Comparison of anatomic and neurophysiological methods for subthalamic nucleus targeting. Neurosurgery 49: 477.

24. Lanotte MM, Rizzone M, Bergamasco B, Faccani G, Melcarne A, et al. (2002) Deep brain stimulation of the subthalamic nucleus: anatomical, neurophysiological and outcome correlations with the effects of stimulation. J Neurol Neurosurg Psychiatry 72: 53-58.

25. Nowinski WL, Thirunavuukarasuu A, Liu J, Benabid AL (2007) Correlation between the anatomical and functional human subthalamic nucleus. Stereotact Funct Neurosurg 85: 88-93.

26. Sterio D, Zonenshayn M, Mogilner AY, Rezai AR, Kiprovski K, et al. (2002) Neurophysiological refinement of subthalamic nucleus targeting. Neurosurgery 50: 58-67.

27. Defer GL, Widner H, Marié RM, Rémy P, Levivier M (1999) Core assessment program for surgical interventional therapies in Parkinson's disease (CAPSIT-PD). Mov Disord 14: 572-584.

28. Friedman A, Harat M, Opala G (2003) Konsensus w zakresie wskazań do leczenia operacyjnego choroby Parkinsona. Neurol Neurochir Pol 37: 11-17.

29. Sławek J (2003) Zabiegi stereotaktyczne w chorobie Parkinsona- zasady kwalifikacji chorych w swietle dotychczasowych badań. Neurol Neurochir Pol 1: 215-227.

30. Ząbek M, Sławek J, Harat M (2006) Stymulacja mózgu i rdzenia kręgowego w leczeniu zaburzeń ruchowych oraz zespołów bólowych podstawy teoretyczne i zalecenia praktyczne. Neurol Neurochir Pol 40: 1-

31. Benazzouz A, Breit S, Koudsie A, Pollak P, Krack P, et al. (2002) Intraoperative micro recordings of the subthalamic nucleus in Parkinson's disease. Mov Disorders 17: S145-S149.

32. Gross RE, Krack P, Rodriguez-Oroz MC, Rezai AR, Benabid AL (2006) Electrophysiological mapping for the implantation of deep brain stimulators for Parkinson's disease and tremor. Mov Disord 14: S259-83.

33. Hutchison WD, Allan RJ, Opitz H, Levy R, Dostrovsky JO, et al. (1998) Neurophysiological identification of the subthalamic nucleus in surgery for Parkinson's disease. Ann Neurol 44: 622-628.

34. Pollak P, Krack P, Fraix V, Mendes A, Moro E, et al. (2002) Intraoperative micro- and macro-stimulation of the subthalamic nucleus in Parkinson's disease. Mov Disord 17: S155-S161.

35. Krack P, Fraix V, Mendes A, Benabid AL, Pollak P (2002) Postoperative management of subthalamic nucleus stimulation for Parkinson's disease. Mov Disorders 17: S188-S197.

36. Coenen VA, Prescher A, Schmidt T (2008) What is dorso-lateral in the subthalamic Nucleus (STN)? A topographic and anatomical consideration on the ambiguous description of today's primary target for deep brain stimulation (DBS) surgery. Acta Neurochir (Wien) 150: 1163-1165.

37. Welter M, Navarro SM (2006) Towards standard of surgical care for DBS in PD: The GUIDE-PD Group experience. Tenth International Congress of Parkinson's Disease and Movement Disorders, Movement Disorders 21: 329-708.

38. Krack P, Batir A,Blercom NV, Chabardes S,Fraix V, et al. (2003) Five year follow-up of bilateral stimulation of the subthalamic nucleus in advanced Parkinson's disease. N Engl J Med 349: 1925-1934.

39. Burchiel KJ, Anderson VC, Favre J, Hammerstad JP (1999) Comparison of pallidal and subthalamic nucleus deep brain stimulation for advanced Parkinson's disease: Results of a randomized, blinded pilot study. Neurosurgery 45: 1375-1382.

40. Pinter MM, Alesch F, Murg M, Seiwald M, Helscher RJ, et al. (1999) Deep brain stimulation of the subthalamic nucleus for control of extrapyramidal features in advanced idiopathic Parkinson's disease: one year follow-up. J Neural Transm 106: 693-709. 
Citation: $\quad$ Rola R, Tutaj M, Koziara H, Koziorowski D, Brodacki B, et al. (2016) Optimizing Final Electrode Placement Based on Intraoperative Neurophysiological Evaluation during Subthalamic Deep Brain Stimulation for Parkinson's Disease. J Neurol Neurophysiol 7: 384 . doi: $10.4172 / 2155-9562.1000384$

Page 6 of 6

41. Moro E, Lozano AM, Pollak P, Agid Y, Rehncrona S, et al. (2010) Longterm results of a multicenter study on subthalamic and pallidal stimulation in Parkinson's disease. Mov Disord 25: 578-586.

42. Hu X, Jiang X, Zhou X, Liang J, Wang L, et al. (2010) Avoidance and management of surgical and hardware-related complications of deep brain stimulation. Stereotact Funct Neurosurg 88: 296-303.

43. Mikos A, Pavon J, Bowers D, Foote KD, Resnick AS, et al. (2010) Factors related to extended hospital stays following deep brain stimulation for Parkinson's disease. Parkinsonism Relat Disord 16: 324-328.

44. Xiaowu H, Xiufeng J, Xiaoping Z, Bin H, Laixing W, et al. (2010) Risks of intracranial hemorrhage in patients with Parkinson's disease receiving deep brain stimulation and ablation. Parkinsonism Relat Disord 16: 96-100.

45. Ben-Haim S, Asaad WF, Gale JT, Eskandar EN (2009) Risk factors for hemorrhage during microelectrode-guided deep brain stimulation and the introduction of an improved microelectrode design. Neurosurgery 64: 754-762.
46. Temel Y, Wilbrink P, Duits A, Boon P, Tromp S, et al. (2007) Single electrode and multiple electrode guided electrical stimulation of the subthalamic nucleus in advanced Parkinson's disease. Neurosurgery 61: 346-355.

47. Sansur CA, Frysinger RC, Pouratian N, Fu KM, Bittl M, et al. (2007) Incidence of symptomatic hemorrhage after stereotactic electrode placement. J Neurosurg 107: 998-1003.

48. Binder DK, Rau GM, Starr PA (2005) Risk factors for hemorrhage during microelectrode-guided deep brain stimulator implantation for movement disorders. Neurosurgery 56: 722-732.

49. Hariz MI, Fodstad H (1999) Do microelectrode techniques increase accuracy or decrease risks in pallidotomy and deep brain stimulation? A critical review of the literature. Stereotact Funct Neurosurg 72: 157-169.

50. Chang WS, Kim HY, Kim JP, Park YS, Chung SS, et al. (2011) Bilateral subthalamic deep brain stimulation using single track microelectrode recording. Acta Neurochir (Wien) 153: 1087-1095. 